\title{
A Rare Case of Medulloblastoma with Supratentorial Metastasis Two Years after Treatment
}

\section{Um caso raro de meduloblastoma com metástase supratentorial dois anos após o tratamento}

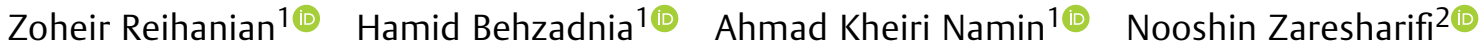 \\ ${ }^{1}$ Department of Neurosurgery, Guilan University of Medical Sciences, \\ Rasht, Iran \\ 2 Department of Pathology, Tehran University of Medical Sciences, \\ Address for correspondence Ahmad Kheiri Namin, Department of \\ Neurosurgery, Poursina Hospital, Namjoo Street, Rasht, 41937- \\ 13194, Iran (e-mail: Ahmadkheyri94@gmail.com).
} Tehran, Iran

Arq Bras Neurocir 2020;39(3):235-238.

\begin{abstract}
One of the most invasive malignant tumors of the cerebellum is medulloblastoma, which is also the most common malignant tumor of the brain in children. Patients with

Keywords

- medulloblastoma

- metastasis

- supratentorial

- recurrence a recurrent disease following initial treatment have the most unfavorable prognosis. The most common metastasis locations are the spine, the posterior fossa, the bones, and the supratentorium. Late medulloblastoma metastasis in the supratentorial intraventricular region is uncommon. We report here a case with supratentorial seeding.

\section{Resumo \\ Palavras-chave \\ - meduloblastoma \\ - metástase \\ - supratentorial \\ - reincidência}

Um dos tumores malignos mais invasivos do cerebelo é o meduloblastoma, que também é o tumor maligno mais comum do cérebro em crianças. Pacientes com a doença recorrente após o tratamento inicial têm o prognóstico mais desfavorável. Os locais mais comuns de metástase são a coluna vertebral, a fossa posterior, os ossos, e o supratentório. Metástase tardia de meduloblastoma na região intraventricular supratentorial é incomum. Relatamos aqui um caso com semeadura supratentorial.
\end{abstract}

\section{Introduction}

One of the most invasive malignant tumors of the cerebellum is medulloblastoma, which is also the most common malignant tumor of the brain in children. ${ }^{1}$ During the last thirty years, developments in imaging, surgery, pathologic stratification, radiotherapy, and chemotherapy have improved the rate of long-term survival or cure in children. The outcome for infants, adults, and high-risk patients is less favorable. ${ }^{2}$ Patients with a recurrent disease after the initial treatment have the most unfavorable prognosis. ${ }^{3}$ The most common metastasis locations are the spine, the posterior fossa, the bones, and the supratentorium. ${ }^{3}$ It has been reported that supratentorial metastasis is more common within the subfrontal region, ${ }^{3,4}$ while late medulloblastoma metastasis in the supratentorial intraventricular region is uncommon. We report here a case with supratentorial seeding.

\section{Case Presentation}

A 4-year-old girl was diagnosed with medulloblastoma, which was confirmed by histopathology and immunohistochemistry staining, causing headache, nausea, vomiting, and vertigo. Thirty sessions of radiation therapy and gross total tumor resection were included in the treatment. Furthermore, shunt placement was performed after the surgery because of the received

March 18, 2020

accepted

April 22, 2020
DOI https://doi.org/

10.1055/s-0040-1713093. ISSN 0103-5355.
Copyright ( 2020 by Thieme Revinter

Publicações Ltda, Rio de Janeiro, Brazil
License terms

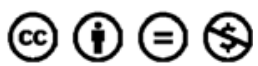



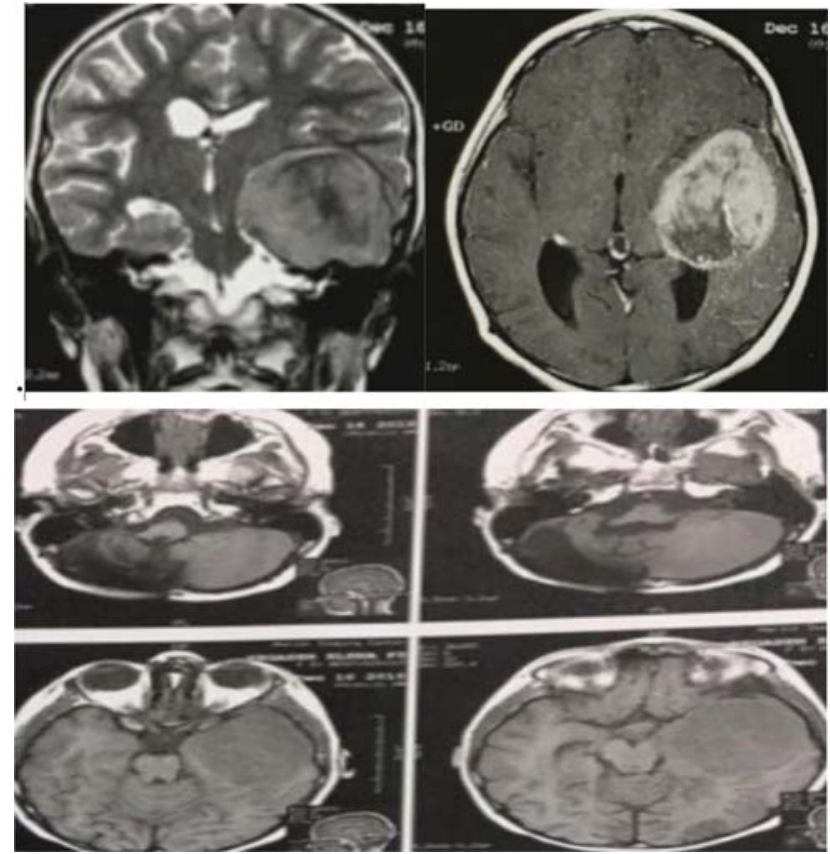

Fig. 1 Brain MRI showing postoperative changes and cavity within the right cerebellar hemisphere, as well as a new T1 low, T2 high signal intensity intracranial enhancing mass lesion within the left temporal lobe measuring $\sim 68 \times 58 \times 46 \mathrm{~mm}$.

hydrocephalus observed in the patient. No spinal metastatic dissemination was found in the postoperative staging. The patient had no complaints in the routine clinical follow-ups, showing normal physical and intellectual development. Local tumor recurrence or spinal drop metastasis were not found by surveillance magnetic resonance imaging (MRI) scans. The patient started a subtle history of restlessness and headache after two years. She was alert and had no focal neurological deficit on admission.
In the following brain MRI with and without contrast, a new well-defined intra-axial mass lesion was reported within the left temporal lobe, with mass effect and left to right midline shift, most likely a metastatic lesion or high-grade primary glioma ( $\mathbf{- F i g} . \mathbf{1}$ ). A brain computed tomography (CT) scan also showed a hyperdense mass within the left temporal lobe (-Fig. 2).

The patient underwent resection of the left temporal lobe lesion, which was diagnosed as medulloblastoma according to the pathology report ( - Fig. 3 ).

With the history of cerebellar medulloblastoma two years before, the new developing lesion within the left temporal lobe is highly suggestive of intracranial supratentorial tumor metastasis.

\section{Discussion}

The prevalence of medulloblastoma is higher in males than in females, accounting for a higher percentage of brain tumors in children than in adults. ${ }^{5}$ The top presenting attributes of medulloblastoma are usually relevant to hydrocephalus and cerebellar dysfunction, including nausea/vomiting, headache, unsteady gait, and truncal ataxia. ${ }^{3}$ Almost $83 \%$ of tumors in children are observed in the midline, while, $49 \%$ of tumors in adults are lateral. ${ }^{6}$ In case of metastasis, recurrence at just one location and further from the primary diagnosis time are known as more desirable prognostic indeces. ${ }^{7}$ The posterior fossa, the spine, the supratentorium, and the bones respectively are the locations in which metastases most typically occurred. ${ }^{3}$ Supratentorial diffusion is generally within the sub-frontal region and maybe consequently of overly great radiation guarding of the orbital roof to inhibit irradiation of the cribriform plate, enabling a nidus of relapse. ${ }^{8}$ Ramaswamy et $\mathrm{a}^{9}$ published the largest series of recurrent medulloblastoma in patients who were mostly younger than 16 years of age. They

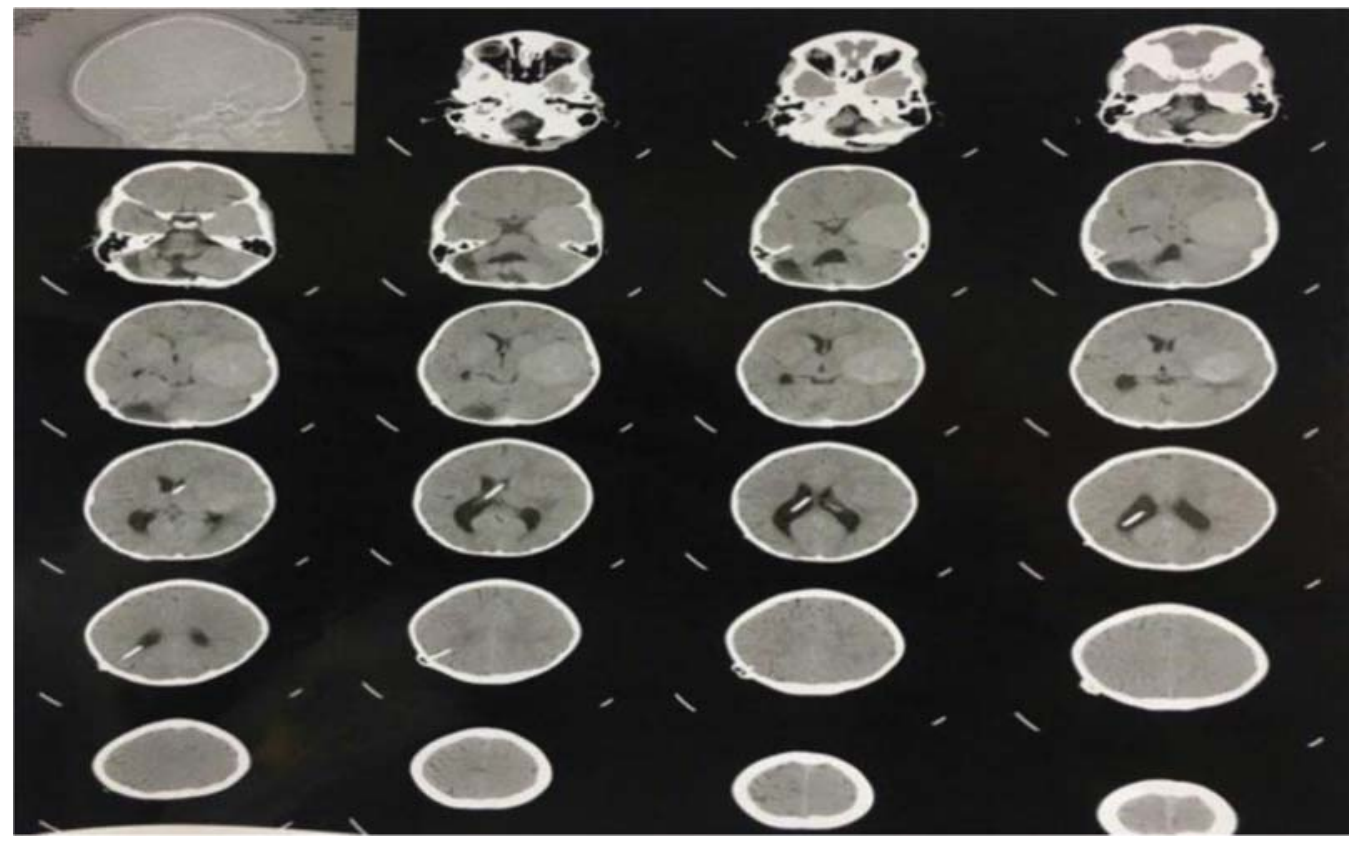

Fig. 2 Brain CT scan. 

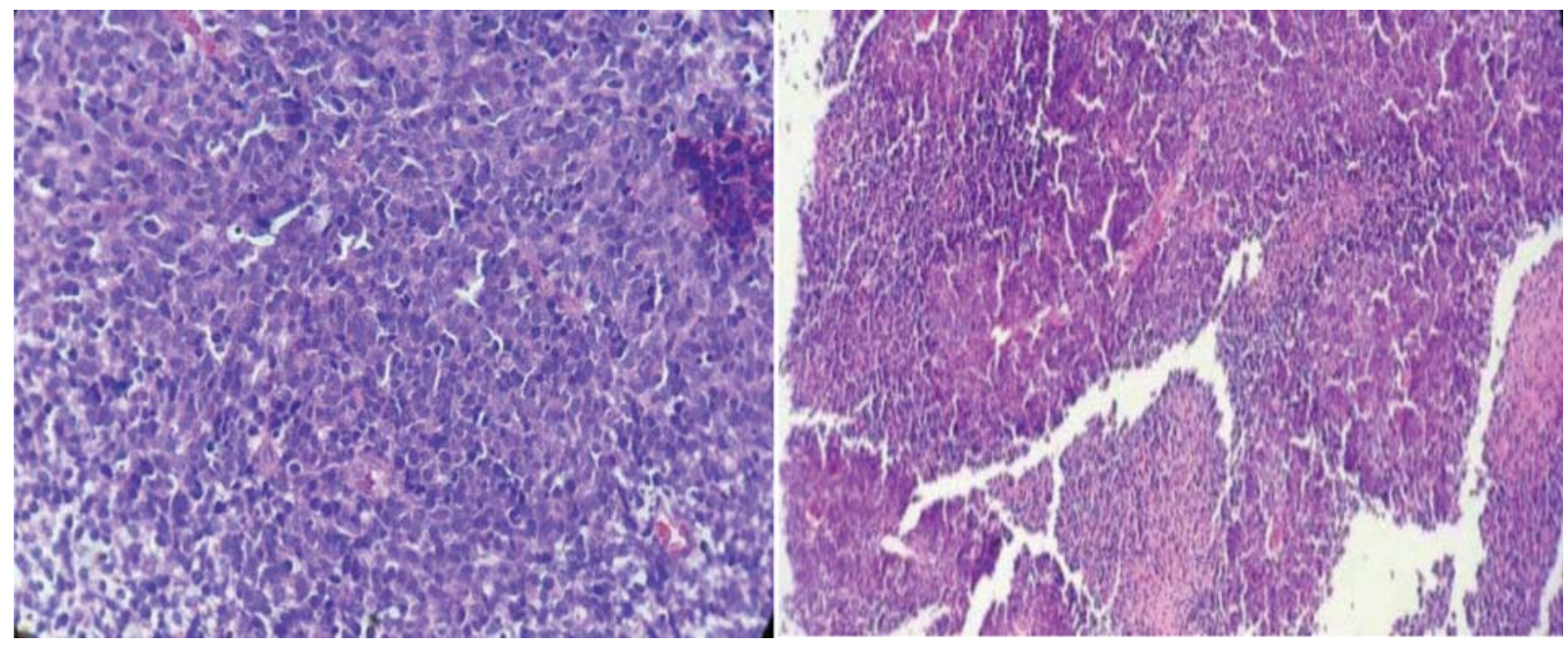

Fig. 3 The tumor cells stained positive for synaptophysin and neuron-specific enolase (NSE), and negative for LCA (Leukocyte common antigen), CD 99 (Cluster of differentiation), and glial fibrillary acidic protein (GFAP) on the immunohistochemistry staining (only hematoxylin and eosin [H\&E] slides available).

found distant metastasis as the most common pattern of tumor relapse compared with local relapse. Kumar et $\mathrm{al}^{10}$ reported 2 adults with the ages of 31 (case 1 ) and 20 (case 2) years, who had metastasis in the supratentorial region 3.5 years and 11 months respectively after total elimination of the medulloblastoma in the posterior fossa. The 31-year-old adult had spinal metastasis as well. Both patients had undergone cranio-spinal irradiation. Case 1 underwent laminectomy, and case 2 was submitted to craniotomy due to the presenting signs. ${ }^{10}$ Abode-Iyamah et $\mathrm{al}^{5}$ reported the case of a 22 -yearold male presenting with isolated, separated pellucidum relapse of the medulloblastoma 13 years after the primary recognition. His tumor was completely resected. Gerlach et $\mathrm{al}^{11}$ reported the case of a 15 -year-old girl presenting with nausea and headache. A brain MRI scan revealed a leptomeningeal spread five years after a surgery for posterior fossa medulloblastoma and following chemoradiotherapy. The biopsy of the left frontal mass showed an extension of the tumor. The histopathological features of the tumor were similar to that of the primary one.

The metastases of medulloblastomas usually happen through the pathway of the cerebrospinal fluid, the ventricular system, and the spinal cord. The extra-neural metastases of primary tumors of the brain are relatively uncommon, and most regularly arise from medulloblastomas in children, and after the adjustment to the incidence of the primary tumor in adults. ${ }^{12}$ The mechanisms of extra-neural medulloblastoma spread remain unknown. Surgical interventions and craniotomy interrupt the blood-brain barrier mechanically and enable the immigration of the tumor cells. Lymphatic and hematogenic (including the retroauricular and cervical lymph nodes) extensions of the primary tumor of the brain have already been proposed. ${ }^{13,14}$ Another often proposed mechanism for the extra-neural extension of the medulloblastoma is iatrogenic diffusion through ventriculo-peritoneal shunts, which are primarily likely to result in peritoneal metastases. ${ }^{14}$ Many extra-neural medulloblastoma metastases happen relatively early after the primary diagnosis. While in $80 \%$ to $85 \%$ of the pediatric cases the posterior-fossa and leptomeningeal metastases are diagnosed in the first 5 years, nearly $80 \%$ of the extraneural metastases are observed within the first 3 years after the primary diagnosis. ${ }^{13,14}$ Simultaneous involvement of the central nervous system and the liver or pulmonary metastasis, early expansion of the extra-neural metastasis (less than 18 months after the primary diagnosis), and patients younger than 16 years of age during the time of the diagnosis of the extra-neural metastasis are typically related to more mediocre forecasts. ${ }^{14}$

\section{Conclusion}

We conclude that the possibility of tumor recurrence or intra-cranial metastasis should always be considered in children with medulloblastoma, and it is recommended that the patients continue to undergo regular treatments and follow-ups for early diagnosis.

\section{Conflict of Interests}

The authors have no conflict of interests to declare.

\section{References}

1 Thomas A, Noël G. Medulloblastoma: optimizing care with a multidisciplinary approach. J Multidiscip Healthc 2019;12:335-347

2 Packer RJ, Gajjar A, Vezina G, et al. Phase III study of craniospinal radiation therapy followed by adjuvant chemotherapy for newly diagnosed average-risk medulloblastoma. J Clin Oncol 2006;24 (25):4202-4208

3 Sun L-M, Yeh S-A, Wang C-J, et al. Postoperative radiation therapy for medulloblastoma-high recurrence rate in the subfrontal region. J Neurooncol 2002;58(01):77-85

4 Roka YB, Bista P, Sharma GR, Adhikari D, Kumar P. Frontal recurrence of medulloblastoma five years after excision and craniospinal irradiation. Indian J Pathol Microbiol 2009;52(03):383-385

5 Abode-Iyamah KO, Winslow N, Flouty O, Kirby P. Isolated Supratentorial Intraventricular Recurrence of Medulloblastoma. J Korean Neurosurg Soc 2015;58(06):557-559

6 Sarkar C, Pramanik P, Karak AK, et al. Are childhood and adult medulloblastomas different? A comparative study of 
clinicopathological features, proliferation index and apoptotic index. J Neurooncol 2002;59(01):49-61

7 Massimino M, Casanova M, Polastri D, et al. Relapse in medulloblastoma: what can be done after abandoning high-dose chemotherapy? A mono-institutional experience. Childs Nerv Syst 2013; 29(07):1107-1112

8 Miralbell R, Bleher A, Huguenin P, et al. Pediatric medulloblastoma: radiation treatment technique and patterns of failure. Int J Radiat Oncol Biol Phys 1997;37(03):523-529

9 Ramaswamy V, Remke M, Bouffet E, et al. Recurrence patterns across medulloblastoma subgroups: an integrated clinical and molecular analysis. Lancet Oncol 2013;14(12):1200-1207

10 Kumar S, Handa A, Jha DK, Choudhary A. Supratentorial metastasis of medulloblastoma in adults. Asian J Neurosurg 2016;11 (03):320
11 Gerlach R, Kieslich M, van de Nes J, Galow W, Seifert V. Supratentorial leptomeningeal metastasis of a medulloblastoma without cerebellar tumor recurrence. Acta Neurochir (Wien) 2002;144 (02):201-204, discussion 204

12 Kondoff SI, Milev MD, Laleva LN, et al. A case of early extraneural medulloblastoma metastases in a young adult. Asian J Neurosurg 2015;10(04):331-333

13 Michalski J, Janss A, Vezina G, et al. Results of COG ACNS0331: a phase III trial of involved-field radiotherapy (IFRT) and low dose Craniospinal irradiation (LD-CSI) with chemotherapy in average-risk Medulloblastoma: a report from the Children's oncology group. Int J Radiat Oncol Biol Phys 2016;96(05):937938

14 Rickert $\mathrm{CH}$. Extraneural metastases of paediatric brain tumours. Acta Neuropathol 2003;105(04):309-327 